\title{
APUNTES PARA UNA HISTORIA DE LA NOVELA DEL SIGLO XIX EN CÁDIZ: IMPRENTAS, LIBRERÍAS, AUTORES Y TRADUCCIONES.
}

\author{
José López Romero.
}

This paper offers some data about the bookshops in Cadiz in the Nineteenth Century, the books, the authors and the translations.

Si discutibles son, por lo exageradas, las opiniones de ciertos historiadores y cronistas de Cádiz en su apreciación del excelente ambiente cultural que se respiraba en la ciudad en el pasado siglo ${ }^{1}$, llevados la mayoría de ellos por un afán propagandístico, algo de verdad sí consideramos que subyace en esa visión un tanto distorsionada que nos han dejado de la cultura gaditana.

Una serie de acontecimientos fundamentalmente políticos, pero también económicos y culturales, tiene lugar en Cádiz a lo largo del siglo XIX que contribuye poderosamente a hacer de esta ciudad una de las más importantes de España, entre estos acontecimientos podemos contar: la resistencia a las tropas napoleónicas en la Guerra de la Independencia; la elaboración y posterior promulgación de la Constitución en 1812; y, sobre todo, el esplendor económico que vivió y del que disfrutó Cádiz a lo largo de casi todo el siglo XVIII, coyuntura que a pesar de caer de forma paulatina pero inevitable durante la centuria siguiente, dio origen a una clase burguesa mercantil, tanto nacional como extranjera, que unió a sus ocupaciones profesionales una fuerte preocupación por la cultura ${ }^{2}$. Uno de los ejemplos más elocuentes de esta burguesía puede ser el de Don Juan Nicolás Böhl de Faber, un hamburgués que se instaló en Cádiz a finales del siglo XVIII, donde su padre había establecido una casa comercial. Sus quehaceres mercantiles no le impidieron dedicarse a las

\footnotetext{
${ }^{1}$ Valgan como ejemplos los recogidos por Alberto Ramos Santana en su La burguesía gaditana en la época isabelina (Cádiz, Cátedra Adolfo de Castro, 1987): "Alfonso de Aramburu afirmaba que "la Cultura constituye, pues, la tinta común, el fardo general de hombres y mujeres gaditanos.... Más específico, y también más propagandístico y tópico, es Federico Rubio, quien afirma de los gaditanos: "No creo necesario hacer muchos esfuerzos para demostrar su superior cultura. Todo el mundo lo reconoce, propios y extraños. No es cultura científica ni artística lo que descuellan, es otra que vale tanto o más. Es cultura social, finura de trato, delicadeza de sentimientos, soltura de expresión y de modales, porte elegante y al mismo tiempo sencillo, modesto, decoroso y distinguido" (p.393).

${ }^{2}$ La actitud del comerciante gaditano ante la cultura es descrita sucintamente por Ramón Solís: "El comerciante gaditano era generalmente hombre culto. Había en la ciudad una constante preocupación por el estudio y un alto nivel de preparación, como lo ponen de manifiesto las colecciones de arte, las bibliotecas, las tertulias -verdadero refinamiento social- y el amor al teatro.", Ibidem, pp. 394-395.
} 
letras, pasión que transmitiría a su mujer y a su hija, la célebre Cecilia Böhl de Faber, Fernán Caballero. Y es precisamente este alemán afincado en Cádiz quien dará lugar a uno de los acontecimientos literarios más señalados de la época: su controversia con José Joaquín de Mora, llamada también la "querella calderoniana", que sostuvo en la década de los años veinte del pasado siglo y cuyo proceso no viene al caso en estas páginas; polémica que está considerada como uno de los hitos o jalones más importantes para la historia del movimiento romántico en España, como así lo ha hecho ver la abundante crítica que sobre ella se ha ocupado.

Marcada, por tanto, la vida de la ciudad por los sucesos de todo tipo que en ella tuvieron lugar, no es de extrañar que éstos repercutan e influyan en ciertos ámbitos de manera especial y a veces determinante. Tal es el caso de la cultura, representada para el propósito que nos guía, por la proliferación de imprentas, librerías y, más específicamente, por la abundante literatura narrativa que se publica en Cádiz a lo largo del siglo XIX.

En cuanto a las imprentas, con la constatación del número de periódicos que en esta época aparecen, aunque pocos se pueden mantener debido a la repercusión que los avatares políticos tenían sobre este tipo de publicación, nos sería suficiente para mostrar la excelente salud de la que disfrutaba el negocio de la imprenta en Cádiz $z^{3}$. Pero la importancia en el marco cultural de una ciudad que tuvieron las imprentas en el pasado siglo no se mide exclusivamente por las publicaciones periódicas que salen a la luz, con ser ésta una de sus tareas más relevantes, sino también por su función en la propagación de otro género de publicaciones, en concreto, para lo que aquí nos interesa, de la novela. Y para ello, menester será describir antes de nada los múltiples trabajos que podía desempeñar una imprenta en el siglo XIX y las variadas tareas a las que se dedicaba. A las labores propias de toda imprenta y taller de litografía, se le podía añadir la publicación de libros, fueran éstos tratados o manuales muy del gusto de la época, en especial de Historia y Derecho, fueran textos religiosos, o incluso libros de creación literaria en todos sus géneros. Pero también estas imprentas podían constituirse en librerías, o en despachos de libros y hasta en almacén de papel. Pongamos un ejemplo ilustrativo al respecto: en la Guía oficial de Cádiz de 1880 se anuncia la "Librería de don Nicolás Sibello, calle de San Francisco, núm. 70.”, y se nos describe pormenorizadamente en la misma publicidad todo lo que el cliente puede encontrar en dicho establecimiento:

"Surtido completo de libros de Ciencias, Artes, Literatura, Religiosos, Marina, Educación y Recreo. Diarios de Navegación y Cuadernos de bitácora. Obras dramáticas y líricas.

Encuadernaciones de todas clases. Libros en blanco y rayados. Impresiones y litografías, y cuanto se relaciona con el ramo de la librería.

Se admiten suscriciones [sic] á todo los periódicos españoles y extranjeros.

Papel, sobres y efectos de escritorio.

\footnotetext{
3.Para las publicaciones periódicas, véase especialmente Ramón Solís, Historia del periodismo gaditano 1800 1850 (Instituto de Estudios Gaditanos, San Fernando, 1971).
} 
Este establecimiento se hace cargo de proporcionar con la mayor brevedad todas las obras que se deseen, tanto nacionales como extranjeras." ${ }^{4}$

De esta especie de imprentas-librerías, J. I. Ferreras, por datos suministrados por Hidalgo y Vicens Vives, certifica la existencia en Cádiz en los años 1848 y 1849 de 18 establecimientos $^{5}$. Y señal inequívoca de la pujanza de éstos y su estrecha relación con el ambiente cultural de la ciudad, es no sólo el número de este tipo de comercios que van aumentando año tras año, sino también el repertorio de libros o publicaciones que ofrecían a sus clientes ${ }^{6}$ y, como consecuencia de ello, las abundantes y bien surtidas bibliotecas privadas fruto éstas principalmente de los desvelos culturales de la burguesía gaditana ${ }^{7}$.

Pero como no hay que olvidar que ante todo una librería no es más que un negocio, dos características o condiciones se unen de forma indisoluble en toda época en el viejo principio económico de la oferta y la demanda: es necesario satisfacer los gustos de aquel que puede permitírselos; o dicho de otro modo y aplicado a nuestra intención, la literatura que se ofrecía en estos establecimientos iba dirigida al público que podía comprarla, y en este sentido se dieron a la imprenta fundamentalmente "el sainete, los poemas, piezas dramáticas y sobre todo "El Novelón", leído igual por Isabel II, que por el miliciano de morrión, por el general O’Donell, presidente del consejo o apocalíptico tribuno Ríos Rosas, y la vieja portera madrileña, es el símbolo de toda una época... Ya la Revista Gaditana decía en 1839 que la novela era el género más adecuado de la sociedad burguesa, por ser popular y democrático"». Y en verdad que todas las imprentas-librerías a lo largo de todo el siglo XIX se dedicaron a satisfacer esos gustos, esto es, a publicar esos novelones de tanto éxito en la centuria. De esto precisamente, de la relación de obras y de las imprentas que en Cádiz las publicaron, nos vamos a ocupar a continuación.

Si hacemos un somero repaso por las referencias que nos ofrece Ramón Solís en su libro sobre la historia del periodismo gaditano, podemos comprobar el número de imprentas que a lo largo de la primera mitad del siglo XIX se dedicaban fundamentalmente a la publicación de periódicos, tarea, como ya señalábamos con anterioridad, la más importante en que se ocupaban estos establecimientos. Entre éstos podríamos destacar por su volumen de trabajo en esta época la imprenta de Manuel Ximénez Carreñoº, sita en la calle de San

\footnotetext{
4.J.Rosetty, Guía oficial de Cádiz, su provincia y su departamento, (Cádiz, Imprenta de la Revista Médica, 1880), p. 153.

5.J.I. Ferreras, La novela por entregas. 1840-1900 (Madrid, Taurus, 1972), pp. 42-43.

6." Sin salir de Cádiz se podían comprar buen número de libros en las varias librerías que había en la ciudad. Librerías bien surtidas, a juzgar por el catálogo impreso de las obras puestas a la venta en la librería de los Sres. Verdugo Morillos y Cía., que ofrecían más de 6.000 volúmenes a la venta", A. Ramos Santana, Op. cit., p. 399.

7."Pero mención aparte merecen las bibliotecas privadas, que eran la manifestación más notable del afán de adquirir cultura que dominaba a los burgueses gaditanos", Ibidem, p. 399. Sobre este tema véase también Pablo Antón Solé, "Bibliotecas y bibliófilos gaditanos", en Archivo Hispalense, 176,(Sevilla, 1971), pp. 41-58.

${ }^{8}$ A. Ramos Santana, Op. cit., pp. 401-402.

9.José Cebrián García en su excelente estudio sobre el impresor Luis de Luque y Leyva, señala que cuando éste intentó instalarse en Cádiz “...debió darse cuenta -hacia 1784- que nunca llegaría a convertirse en uno de los impresores más solicitados de Cádiz. Eran tiempos de prosperidad -es cierto- pero también de dura competencia por alzarse con los encargos. Pedro Gómez de Requena, el impresor mayor, y Juan y Manuel Ximénez Carreño, sus más encarnizados
} 
Miguel por 1786, año en que publicó una edición de La Pensadora Gaditana ${ }^{10}$, para más tarde imprimir el Diario Mercantil (1802), algunos números de El Conciso (1810-1813), y a principios de la segunda década del siglo pasado publicar algunos opúsculos sobre la contienda desatada en la ciudad entre ciertos hombres ilustres y el siempre polémico "Clara-rosa" "1. Pero a esta labor en la difusión de la prensa periódica, también hay que añadir la publicación de novelas, y en este sentido sólo disponemos de una referencia: la obra de Rafael Leal titulada El lavandero de Madrid y trapizondas (sic) de la Corte, o sea vida del español Don Guillermo Atanasio Xaramillo' ${ }^{12}$. De acuerdo con esta referencia, es obligado suponer que la labor editora de la imprenta de Ximénez Carreño no se reduciría sólo y exclusivamente a esta obra y que algunos títulos más publicaría, aunque de ellos no nos haya quedado constancia por el momento.

Otro de estos establecimientos tipográficos que desempeñó una excelente labor en la difusión de periódicos y novelas a lo largo de buena parte del siglo XIX, fue la imprenta llamada La Sincera Unión, propiedad del célebre "Clara-rosa". En ella publicará su Diario Gaditano $^{13}$ (1820) y dos años después El Gorro. Finalmente, a la muerte de su propietario, la imprenta pasará a cargo ya del "ciudadano J.G. Maza", quien publicará el periódico $E l$ Constitucional de Cádiz. Y ya bajo la dirección de Maza, encontramos una novela impresa en La Sincera Unión: Rafael de Riego o la España libre, cuyo autor es Francisco Brotons y que se publica en $1822^{14}$.

adversarios, luchaban por aquel entonces por la primacía”. J. Cebrián, D. Luis de Luque y Leyva y sus imprentas (Jerez de la Fra., Caja de Ahorros, 1985) p. 63.

${ }^{10}$.Sobre esta publicación nos dice J.I. Ferreras: "Hay un fenómeno curioso a finales del XVIII que demuestra bien a las claras, la extensión del lectorado femenino, me refiero a la obra costumbrista que con el título general de La Pensadora Gaditana se publicó en Cádiz en 1786; esta publicación apareció firmada con el seudónimo de Beatriz Cienfuegos, seudónimo que al decir de toda la crítica, corresponde a un hombre. ¡Y qué mayor prueba de la existencia de un lectorado femenino que el empleo de un seudónimo de mujer por parte de un hombre!, J.I. Ferreras, Los orígenes de la novela decimonónica. 1800-1830, (Madrid, Taurus, 1973) p. 56. Sobre La Pensadora Gaditana, véase ahora la edición antológica de Cinta Canterla (Publicaciones de la Universidad de Cádiz, Cádiz, 1996).

${ }^{11}$ En 1820 publica la imprenta de Carreño el opúsculo del Padre Laso de la Vega "Verdades católicas contra los errores contenidos en la Teoría para la organización de una Concordata por el ciudadano Clara-rosa". Y al año siguiente, 1821, en la misma imprenta pasada ya a manos de los herederos de D. Manuel Ximénez, a cargo de su hijo y ubicada en la calle Ancha, se da a luz "Esplendor del Ilustrador de Cádiz" escrito por José Fernández de Castro. Estas noticias en R. Solís, Op. cit., pp. 174 y 191. Por otra parte, "Clara-rosa" es pseudónimo de José Joaquín de Olavarrieta, que fue sacerdote en Méjico, editor de periódicos, escritor de libros, liberal exaltado y masón. Murió preso en Cádiz.(Ver J.I. Ferreras, Catálogo de novelas y novelistas españoles del siglo XIX (Madrid, Cátedra, 1979) págs. $107\left(n^{\circ} 528\right)$ y $289\left(n^{\circ} 1466\right)$.

${ }^{12}$ En J.I.Ferreras, Catálogo de novelas..., p. 214 (n 1056). Ferreras añade: “... La obra que señalo puede ser una novela satírica muy estilo siglo XVIII.... Cádiz 1812, 72 págs., 4 ${ }^{\circ}$ Impr. de Don Manuel Ximénez Carreño.

${ }^{13}$. Diario gaditano de la libertad e independencia nacional, político, mercantil, económico y literario. La imprenta estaba ubicada primero en la calle de San Ginés, n², más tarde en la calle de la Torre $n^{\circ} 23$ y por último en la casa donde vivía el mismo "Clara-rosa", en la Alameda, esquina a la calle Linares. R. Solís, Op.cit., p.171.

${ }^{14}$ En J.I. Ferreras, Catálogo de novelas..., p. 85, n 406. Manejamos también para las novelas españolas las adiciones de Amancio Labandeira al Catálogo de Ferreras: "Adiciones y precisiones a un catálogo de novelas y novelistas españoles del siglo XIX”, en Boletín Millares Carlo, vol. 1, n² 2 (1980); "Identificaciones en un catálogo de novelas y novelistas españoles del siglo XIX", en Revista de Estudios Hispánicos, XVI, n 3; "Adiciones a un catálogo de novelas y novelistas españoles del siglo XIX", en Cuadernos para la investigación de la Literatura Hispánica, n $^{\circ} 4$ (1982); y "Precisiones biográficas y bibliográficas en un catálogo de novelas y novelistas españoles del siglo XIX", en Cuadernos para la Investigación de la Literatura Hispánica, nº 6 (1984). 
La imprenta de Manuel Bosch también desempeñó una enorme labor en la materia que estamos tratando. Entre los años 1808 y 1810 se publican en Cádiz varios periódicos, entre ellos el titulado Noticias fidedignas y el que para R. Solís será el más importante de estos años: Noticia exacta de lo ocurrido en la plaza de Cádiz e isla de León, cuyo editor era don F.E. Castrillón; ambos periódicos salen de los talleres de Manuel Bosch. Y en 1834 encontramos una novela impresa en esa misma casa, aunque ya la titularidad del establecimiento hubiera pasado a la viuda del impresor, nos referimos a Novela Histórica. Sucesos y aventuras del joven valenciano $D$. Vicente Oferral en su viaje a Italia. Escrita por D.J.M.G. ${ }^{15}$; y años más tarde se publicará en esta imprenta la traducción de El maestro de escuela de Frédéric Souliér ${ }^{16}$. Y aunque sólo encontremos estos dos títulos, habría que suponerle a la imprenta de Bosch la importante tarea que desarrollaría en la difusión de la novela española y extranjera a lo largo del siglo XIX, ya que no sólo se constituyó como tal taller de tipografía, sino que también y en el mismo domicilio de la calle Verónica 153 abrió una librería, como así lo atestigua la Guía oficial de Cádiz del año 1853. Sus noticias nos llegan hasta $1867^{17}$.

Otro de los establecimientos que encontramos en la primera mitad del siglo XIX dedicado a la impresión de periódicos y novelas es el de José María Guerrero. En 1811 publica por vez primera un periódico totalmente en verso, El Poeta Andaluz, y muchos años más tarde, en 1860, da a la luz la novela de Timoteo de la Paz Sacristán Valentín ${ }^{18}$. En las distintas Guías oficiales posteriores a ese año, varios son los cambios que observamos en la imprenta de J.M. Guerrero. En la de 1867 la propiedad la ostenta D. Nicolás Guerrero y Humbría, y su domicilio es S. José 52. En 1872 el titular es D. Alejandro Guerrero y Acedo, para ya en 1880 pasar a llamarse bajo la misma dirección de D. Alejandro Guerrero Imprenta del Boletín Oficial, y domiciliarse "el despacho en S. Francisco 35 y los talleres en Arbolí 6"19. Finalmente, en 1888 esta misma Imprenta del Boletín Oficial pasará a la propiedad de D. Ildefonso Prieto en la calle Sacramento 48.

La imprenta de J.A. Niel puede representar uno de esos negocios tipográficos que, como estamos comprobando por las notas anteriores, tanta fortuna tuvieron en Cádiz a lo largo del siglo pasado, negocios familiares que alargarían su existencia, como el antes nombrado de J.M. Guerrero o el de Ximénez Carreño o incluso el de Manuel Bosch, hasta bien entrada la segunda mitad del XIX. Ya en 1812 publica Niel el periódico La Década, en los talleres que tenía en la calle del Baluarte; y entre 1838 y 1841 inicia una colección de novelas originales a la que denominará "Biblioteca de Señoritas". Según Ferreras, se publicaron en estos años al menos 5 volúmenes, entre los que contamos El proscripto en tres tomos (1838) y El Gayumbo de los menoristas en dos volúmenes, novelas que aunque

\footnotetext{
15.Ibidem, “... Cádiz 1834, 2vols., 8, Impr. Viuda de Bosch”, p. 281, nº 1433.

${ }^{16}$ En José Fernández Montesinos, Introducción a una historia de la novela en España en el siglo XIX, p. 246: “... Viuda e hijo de Bosch, 16"'.

${ }^{17}$ En la Guía oficial de Cádiz y su departamento para el año de 1853, (Cádiz, Impr. de D. Filomeno Fernández de Arjona, C/ de la Torre, n58, 1852) pp. 54-55. En la Guía de 1867 de José de Rosetty, se observa un cambio en el domicilio de la Imprenta de Bosch: "Verónica, 11" (p. 291).

18.J.I. Ferreras, Catálogo de novelas..., “... Novela original. Cádiz 1860, 220 páginas, 16 mayor”, pág. 309, n 1536.

19.J. Rosetty, Guía ofical de Cádiz.. para 1880, (Imprenta de la Revista Médica, 1880) p. 300.
} 
anónimas se le adjudican a El Señor de la Laguna ${ }^{20}$. Las noticias de esta imprenta alcanzan hasta 1900, año en que la encontramos bajo la denominación de "Viuda de Niel" y sita en la calle $S$. Francisco $n^{\circ} 2$.

La Imprenta Gaditana, cuyo propietario era Esteban Picardo, será otra de las que se distinguieron ya desde principios del XIX por su ingente labor. En sus talleres se imprime en 1817, como señala R. Solís, un opúsculo titulado Loor al Muy Noble y Muy Leal y Muy Heroico pueblo de Cádiz, a su Excmo. Sr. Gobernador y Cabildo y Loor eterno al Autor de la Memoria Histórica Gaditana, firmado por don Rupecindo Roquel. Se encontraba esta imprenta por ese año en la calle de la Carne, núm. 186 21 . Años más tarde, concretamente en 1820 y 1821 , publicará este mismo establecimiento diversos opúsculos referentes a otras tantas polémicas de carácter político que se desataron en la ciudad por aquellas fechas; por ejemplo, la Contestación al Mariscal D. Antonio Quiroga edecan del Rey, y segundo General del Ejército de Andalucía, que escribe Santiago Rotalde, director por otra parte del periódico El Telescopio político; o la serie de escritos que se cruzan Juan Bautista Cavaleri Pazos y José Manuel Vadillo, todos publicados en la misma imprenta de Picardo. A esto, habría que añadir la labor que para el tema propuesto se nos antoja más importante: la publicación de los trece primeros números, entre los años 1839 y 1840, de la famosa Revista Gaditana. Publicación ésta semanal que prolonga su vida desde el 3 de noviembre de 1839 hasta el 12 de julio de 1840, y que será una de las más destacadas de su época. En la descripción que Virtudes Atero nos hace de esta revista en dos excelentes trabajos a ésta dedicados $^{22}$, se puede comprobar la importancia que este tipo de publicaciones tuvo en su momento en la difusión de la cultura y, muy especialmente, en el desarrollo de la novela. En los tres primeros números se publica íntegra la novela de José Bermúdez de Castro La hechicera. Entre los números 4 y 9 se publica también la novela titulada La Alameda del Perejil. Novela Gaditana, cuyo autor es Francisco Flores Arenas ${ }^{23}$. En el número 10 encontramos también un cuadro de costumbres titulado Una boda en Madrid. Novela original de costumbres, firmado con el psudónimo de "El Estudiante"; a pesar de la denominación "novela", no alcanza a más de cuatro páginas de la revista y sin continuación en las sucesivas entregas. Y, finalmente, en cuanto a los trece números que de la Revista Gaditana se imprimeron en los talleres de don Esteban Picardo, y en lo concerniente a nuestro tema, digno es de reseñar la traducción de un fragmento de la novela de Edward George Bulwer Lytton Pelhan or the adventures of an English Gentleman, con el título: Un candidato de conciencia. Costumbres inglesas. Pero lo más interesante será la nota de redacción que acompaña a esta traducción, en la que "se especifican que irán apareciendo en la revista diversos escritos de los autores más interesantes del momento en Francia e Inglaterra para mejor comprender sucesivos análisis de su obras" ${ }^{24}$. Y en verdad que una de las tareas más

\footnotetext{
20.Ver J.I. Ferreras, Catálogo de novelas..., pp. 77 ( $\left.\mathrm{n}^{\circ} 351\right), 175\left(\mathrm{n}^{\circ} 851\right), 212\left(\mathrm{n}^{\circ} 1039\right)$ y $328\left(\mathrm{n}^{\circ} 1631\right)$.

${ }^{21}$ R. Solís, Op. cit., p. 89.

22.V. Atero Bürgos, "La Revista Gaditana (1839-1840). Estudio de una revista andaluza", en Gades, 6 (1980) pp. 5-28; y "La Revista Gaditana (1839-1840). Indice de contenidos, en Gades, 12 (1984) pp. 29-76.

${ }^{23}$ Esta novela, según el Catálogo de novelas... de J.I. Ferreras, también se publicó por entregas en "El Semanario Pintoresco Español", en 1852.

24.V. Atero, "La Revista Gaditana... Indice de contenidos", art. cit., pp. 31-44.
} 
relevantes a las que se dedicó la Revista Gaditana en sus siguientes entregas fue a la traducción de obras de autores extranjeros, relación de éstos que veremos posteriormente ya que la revista pasaría a imprimirse en talleres distintos de los que aquí nos ocupan.

Hacia mediados de siglo, Francisco Sánchez del Arco mantendrá en su imprenta, sita en la calle Puerto núm. 8, una dilatada actividad. A la publicación del periódico El Constitucional y a su suplemento Fray Gerundio Gaditano y su lego Tirabeque (1857), hay que añadirle la edición de novelas, entre ellas Ahogarse en la orilla, traducción del francés (1858), El secreto del médico de Madame Roger de Beauvoir (1860), de Emile Greyson Fiamma Colonna, historia belga del siglo XV, y de Madama Melania Waldor Amor de una tienda $(1860)^{25}$.

De la imprenta de Lázaro Estruch sólo constatamos la reseña de una novela salida de sus talleres: la obra de José Arias Bela La hija de Abenabó, subtitulada novela original española, escrita por el autor de las Leyendas Jerezanas ${ }^{26}$.

$\mathrm{Y}$ antes de dedicarnos a analizar la ingente labor que llevaron a cabo las dos imprentas que, según nuestros datos, pueden considerarse las más importantes y de mayor repercusión a lo largo de buena parte del siglo XIX en lo que a publicación de novelas se refiere, nos ocuparemos de una serie de establecimientos tipográficos que también contribuyeron, aunque en menor medida de acuerdo con los datos manejados, a la expansión y popularidad de los llamados "novelones" decimonónicos. Algunos de estos talleres, como ya hemos observado por los casos comentados con anterioridad, se dedican primordialmente a la publicación de periódicos, e incluso se puede decir en ciertos casos que la imprenta pertenece a la propia publicación, la cual le otorga su nombre. Es el caso, por ejemplo, de La Estrella, periódico de literatura, ciencias, artes y modas, de carácter semanal que se publicó entre 1842 y 1843 27; y en él se incluye la publicación de la novela Antonio de Armengol. Barón de Rocafort. Novela original por el autor del Proscripto, entre el número del 24 de julio de 1842 y el correspondiente al del 25 de diciembre del mismo año; de la misma forma y en el mismo periódico se publica entre el 22 de enero y el 5 de febrero de 1843 la novela original de F. Garrido Elena de $S^{* * *}$, y del mismo autor Dos carcajadas $^{28}$. Caso semejante a éste último, es el de la Guía de Comercio, diario de la tarde, mercantil, industrial y estadístico, publicado entre 1858 y $1859^{29}$; en sus talleres también se publicará la novela de Guido Artal El adalid almogávar. Novela histórica original (1859) ${ }^{30}$. El Comercio, periódico político, mercantil y literario, será otro caso como los anteriormente comentados, pero, a diferencia de éstos, su dilatada vida (de 1842 a 1885) le permitirá

\footnotetext{
25.Impreso también en estos talleres, hemos encontrado un curioso opúsculo cuyo autor es el insigne gaditano Adolfo de Castro: Filosofía de la muerte (Cádiz, Impr. Fco. Sánchez del Arco, C/ Juan Rodríguez 8, 1856).

${ }^{26 .}$ Según Ferreras (Catálogo de novelas...), esta novela ha sido atribuida "a tres autores diferentes; por orden alfabético: José Arias Bela, M. Hué y Camacho y José Joaquín Mora (p. 48, n 146). Labandeira, por su parte, señala como autor de las Leyendas y novelas jerezanas a José Reguera Ruiz y Peñaranda (Ronda, Impr. de José Pérez de Guzmán, 1838, 323 pp., 16%), en "Adiciones a un catálogo....", art. cit., p. 81 en "Autores nuevos no indetificados". ${ }^{27}$ En Varios, La prensa gaditana 1763-1936 (Cádiz, Diputación, 1987) p. 52.

${ }^{28}$.Las reseñas de La Estrella, en J.I. Ferreras, Catálogo de novelas..., pp. 46 ( $\left.{ }^{\circ} 124\right)$ y $174\left(n^{\circ} 845\right)$.

${ }^{29}$.En Varios, La prensa gaditana..., p. 56.

${ }^{30}$ En J.I. Ferreras, Catálogo de novelas..., p.50 ( $\left.{ }^{\circ} 160\right)$.
} 
participar más activamente en el ambiente literario de Cádiz. Muchas son las traducciones que a los talleres de este periódico se deben, sobre todo de Balzac y de Eugenio Sue. Del primero se publicaron las Memorias de dos jóvenes casadas (1843) y Escenas de la vida de París. Historia de los trece (1844); y del segundo ¿Es un ángel o un diablo? (1843), Matilde, memorias de una mujer de gran mundo (1843), la celebérrima Los misterios de París (1843) y Teresa Dunoyer (1843). Finalmente, también en esta imprenta se publicó de Paul Féval Los incendiarios de Irlanda en dos volúmenes (1847) $)^{31}$. De la imprenta de $E l$ Globo (1840-1842) también salió una traducción de Eugenio Sue, concretamente de su novela Arturo, en dos volúmenes (1842).

Y si éstos eran los que podríamos denominar Periódicos-Imprentas, de otros establecimientos tipográficos apenas conservamos noticias, quizá debido a la escasa labor que realizaron tanto en la prensa periódica como en la publicación de novelas. Es el caso de la imprenta La Paz, de la constatamos la edición de Doña Blanca de Borbón, leyenda histórica anónima (1858); sin embargo, muy posterior a esta fecha, en la Guía Oficial de Cádiz de 1867, aparece esta imprenta "a cargo de D. Manuel M. de Luque" y situada en "Bendición de Dios 4 y Enrique de las Marinas 31"; por la Guía de 1871 se puede saber que dicho establecimiento pasa a estar al cargo de D. José M. Velasco, manteniéndose en el mismo lugar; para ya en 1885 pasar a manos de D. Faustino Díaz y Sánchez y ubicarse en la calle Flamencos 6. Y con el nombre del nuevo propietario pasará a denominarse a partir del año siguiente ${ }^{32}$. El mismo tratamiento que a ésta puede dársele a la imprenta La Palma, ya que sólo una publicación sacada de sus talleres podemos localizar: la novela de Gabriel Ferri El cazador errante (1860)33. El establecimiento estaba ubicado en la calle Torre 31, según la Guía de 1867, y ya en la de 1871 se señala que estaba a cargo de "D.A.R. y García", para pasar al año siguiente a cargo de D. Francisco González y desaparecer a los pocos años, de tal manera que en la Guía de 1875 ya no se incluye entre las imprentas existentes en la ciudad. Más interesante, en cambio, nos puede resultar la imprenta La Mercantil, de ésta localizamos dos novelas de la misma autora, Patrocinio de Biedma, la primera titulada Fragmentos de un álbum, novela original. Dos hermanas (1884, $2^{\mathrm{a}} \mathrm{ed}$.), y la segunda La Marquesita (1892) ${ }^{34}$. En la Guía de 1890 incluye un anuncio esta imprenta que reza así:

\section{LA MERCANTIL}

ESTABLECIMIENTO TIPOGRAFICO Y EDITORIAL

Fundado por

D. JOSE RODRIGUEZ Y RODRIGUEZ

El año 1868 y establecido calle Cervantes, n. 2

esquina á las de Gaspar del Pino y Benjumeda

\footnotetext{
${ }^{31}$ Las reseñas de todas estas traducciones en J. Fdez. Montesinos, Op. cit., pp. 161, 192 y 249.

32.Ver José de Rosetty, Guía Oficial de Cádiz..., años 1867 y siguientes.

33.J.I.Ferreras en su Catálogo de novelas..., p. 157 ( $\mathrm{n}^{\circ}$ 763), reseña, tomando como fuente a Cejador, esta novela en una edición de Madrid de 1859. Por mi parte, en bibliotecas privadas he encontrado ésta que señalo publicada en Cádiz.

34. Ibidem, p. $78, \mathrm{n}^{\circ} 366$.
} 
En dicho establecimiento se hacen facturas, tarjetas de casa de huéspedes, invitaciones, libros talonarios, papel membretado en colores, etiquetas y circulares de defunción, á cualquier hora del día ó de la noche y á precios bastante arreglados.

CASA EDITORIAL DE LA BIBLIOTECA CERVANTICA, dirigida por D. Ramón León Máinez; de la preciosa obra

\section{ENSAYO HISTORICO-CRITICO DEL TEATRO ESPAÑOL,}

por D. Romualdo Alvarez Espino; del periódico CRONICA DE CADIZ Y SU PROVINCIA, que publica dos ediciones diarias, y de las obras en prosa y en verso de D. Patrocinio de Biedma. ${ }^{35}$

Por esta publicidad podemos conocer con toda exactitud las diversas actividades a que se dedicaban las imprentas de la época; a las propias de lo que ahora llamaríamos papelería (impresión de facturas, tarjetas, invitaciones, etc.), se añadía la edición de pequeñas colecciones de libros ("Bibliotecas"), como se puede apreciar por el titulado Ensayo histórico-crítico del teatro español, la publicación de periódicos (Crónica de Cádiz y su Provincia) y, especialmente importante para el tema que aquí nos ocupa, la edición de obras en prosa y en verso.

Finalmente y antes de ocuparnos, como ya hemos dicho, de los dos talleres tipográficos más importantes en Cádiz en el pasado siglo, valgan las referencias de otras imprentas de las que escasamente hemos podido reseñar alguna publicación. Son los casos de La Alborada (quizá periódico), que edita la novela de Leopoldo Pruneda Una venganza y un arrepentimiento tardío. Novela original (1861); de la imprenta Pinto, en cuyos talleres se imprimió la obra de Luis Mejías Escassy Juan el perdío. Disparate humorístico. Parodia de la segunda parte de Don Juan Tenorio (1866); de la de Uclés, que publica dos traducciones, una de Gabrielle Anne de Courtiras, Condesa de Dash, El castillo de Pinon (1844), y la otra del omnipresente Eugenio Sue, El Comendador de Malta (1844); y las imprentas de Ruiz y de Vélez que traducen sendas obras de Alejandro Dumas, la primera, la novela Las dos Dianas (1848), y la segunda, Jorge (1845) ${ }^{36}$. Finalmente, señalemos la existencia de una colección que, a pesar de desconocer la imprenta de procedencia, al parecer desarrolló una muy interesante labor en la traducción de narraciones extranjeras, nos referimos al "Museo de novelas históricas", colección en la que se incluyen los siguientes autores y obras:

-Arnaud, Henriette (Mme. Charles de Reybaud), El baile del vicelegado, 1842.

-Balzac, Honoré de, Los dos polacos (= La fausse maitresse?), 1842.

-Berthoud, Samuel Henri, Entre mediodía y las dos. Las tortas del príncipe Bedredín. La caldereta de Bicêtre, Cádiz, "Museo de novelas históricas", I y II, 1842.

-Gay, Sofía, María Luisa de Orleans, reina de España, Cádiz, "Museo de novelas históricas", IIII, IV y V. 1842.

-Idem, El perro y el chal, Cádiz, “Museo...”, I.

\footnotetext{
35.J. Rosetty, Guía Oficial de Cádiz.., 1890, p. 143.

36.Para estas últimas reseñas, Vid. J.I. Ferreras, Catálogo de novelas..., pp. 78-79 (n³66), $329\left(n^{\circ} 1635\right)$ y $250\left(n^{\circ}\right.$ 1244); y J. Fdez. Montesinos, Op. cit., pp. 180, 249, 185 y 187.
} 
-Scribe, Eugéne, El rey de oros, Cádiz, "Museo...”, 184237.

Los dos establecimientos a los que hemos aludido anteriormente como los de mayor trascendencia en el panorama cultural de Cádiz a lo largo del siglo XIX, no son otros que las imprentas de Don Filomeno Fernández de Arjona y de la Revista Médica. Una y otra realizaron una dilatadísima labor editorial tanto en publicaciones periódicas como en novelas; de éstas, el mayor contingente que hemos podido recabar pertenecen a estas dos imprentas.

En cuanto a la primera, la de Arjona, y en lo concerniente a periódicos, tenemos noticias de la publicación entre otros del Diario de anuncios de Cádiz (abril-mayo de 1865) y del Faro de Cádiz (1867). La imprenta pasó por muy diversos avatares debidos a los cambios y supuestas asociaciones que pueden deducirse por las reseñas de las novelas que en sus talleres se publicaron. En la calle Torre, núm. 58, se ubicaba la imprenta en 1852 , para ya en 1867 pasar al núm. 27 de la misma calle. En la Guía de 1871 se indica que "los talleres en p. Balon 21 y el despacho c. Torre 27"38. Pero ya a partir del año siguiente, 1872, esta imprenta pasará a llamarse La Ibérica y será su propietario D. Francisco Fernández de Arjona y Núñez, los talleres se mantendrán en p. Balón 21, pero el despacho se trasladará a la calle Duque de Tetuán 12 y posteriormente al núm. 19. A finales de siglo, por las referencias recogidas de las Guías Oficiales, se mantienen la misma denominación de la imprenta, La Ibérica, y su propietario, F. Fernández de Arjona, aunque su domicilio ha pasado a la calle Flamencos, núm. 6, precisamente en el mismo lugar donde se ubicaba, como hemos visto, la imprenta La Paz. Al margen de estos datos, vayamos al tema que aquí nos interesa, que no es otro que la actividad desarrollada por la imprenta Arjona a lo largo de la segunda mitad de siglo XIX en la publicación de novelas. Para ello, no encontramos otra fórmula más acertada que ofrecer el considerable número de obras impresas por ese establecimiento según una relación distribuida en dos grandes apartados: traducciones y novela nacional, para cuyas reseñas nos hemos servido fundamentalmente de los dos catálogos más importantes que sobre la narrativa decimonónica se han publicado, el de José Fdez. Montesinos para las primeras y el de J.I. Ferreras para la segunda, éste último completado con los trabajos de Amancio Labandeira.

\section{TRADUCCIONES.-}

-Bernard, Charles de, La baronesa de Bergenheim, Cádiz, 2 vols., 8,1848-49 ("Biblioteca Económica Popular" $\left.{ }^{\prime 39}\right)[165]^{40}$.

\footnotetext{
${ }^{37}$ La referencia a esta colección en J.I. Ferreras, Catálogo de novelas..., p.270 ( $\left.n^{\circ} 1389\right)$. Y las reseñas de estas novelas en J. Fdez. Montesinos, Op. cit., pp. 158, 161, 165, 198 y 244.

38.J. Rosetty, Guía Oficial de Cádiz... 1871, p. 221.

${ }^{39}$ Sobre esta posible colección hay algunos datos que estimo muy interesante ser comentados. En primer lugar, J.I. Ferreras señala en su Catálogo: "Sólo he logrado ver dos vols., en $4^{\circ}$, con traducciones de Dumas, ¿se publicaron obras originales? Incompleta en la B.N. de M.: 5/3119” (p.68, $\mathrm{n}^{\circ} 273$ ). El mismo Montesinos nos ofrece en su "Esbozo" final de traducciones una de Alejandro Dumas, El bastardo Agenor de Monleon, traducción de José Ignacio de Michelena, Cádiz, La Publicidad, 4 vols. , $8^{\circ}$, "Biblioteca Económica Popular", 1848” (p. 187). Es muy posible, según estos datos, que en la imprenta de Arjona se publicase el periódico La Publicidad y a través de éste se crease una colección de novelas a la que se denominó "Biblioteca Económica Popular" dedicada fundamentalmente a traducciones, como a continuación comprobaremos por la serie de citas que recoge el propio Montesinos.
} 
-Ducange, Víctor, Thelena o El amor y la guerra, traducción de Emilio Polanco, Cádiz, 2 vols., $8^{\circ}, 1847,[182]$.

-Dumas, Alejandro, Gabriel Lambert, trad. de J.I. de Michelena, Cádiz, 2 vols., 8, ("Biblioteca Económica Popular"'41), 1849, [188].

-Idem, El traje de boda, trad. de D.S.C., Cádiz, 2 vols., 8, ("Biblioteca Económica Popular”), 1849, [188-189].

-Idem, La condesa de Salisbury, trad. de D. Evaristo Acuaviva y Galán, 3 vols. 16 mayor, (“Biblioteca Económica Popular”). Contiene también La pesca con redes, trad. de A.G.M., 1850, [189].

-Féval, Paul, Los fanfarrones del rey, trad.de J.I. de Michelena, Cádiz, 2 vols., $16^{\circ}$ mayor, ("Biblioteca Económica Popular”), 1849, [192].

-Kock, Paul de, El amante de la luna, trad. de J.I. de Michelena, Cádiz, 6 vols. 8, ("Biblioteca Económica Popular"), 1847-48, [212].

-Idem, La linda muchacha del barrio, trad. de A.G.M., Cádiz, 3 vols., 16º 1849-50, [212].

-Robert, Clemence, El tribunal secreto, trad. de J.I. de Michelena, Cádiz, 2 vols. 8, ("Biblioteca Económica Popular"), 1848, [234].

-Soulié, Frédéric, Enrique de Lorena, Cádiz, 2 vols. 8, ("Biblioteca Económica Popular”), 1849, [248].

-Sue, Eugène, Martín el expósito, trad. por el joven don Federico Bello y Chacón, Cádiz, (“Biblioteca Popular Gaditana"42), [252].

-Idem, El arte de agradar, Cádiz, 8, 1847, [252].

A esta relación de traducciones, habría que añadir algunas más que Arjona publica en una supuesta o posible asociación con otros que, según los datos manejados, creemos que pueden ser también impresores. Ya hemos visto el caso de Núñez y la "Biblioteca Popular Gaditana" y la traducción de la novela de Eugenio Sue, a la que hay que añadir la de Paul Lacroix (llamado P.L. Jacob), Claudio Lepetit y su mono, trad. de D.J.N.E., Cádiz, Núñez y

\footnotetext{
${ }^{40}$ Señalamos entre corchetes la página de la obra de J. Fdez. Montesinos en que se encuientra la reseña de la novela. ${ }^{41 .}$ Ver nota 39.

42.Sobre esta colección nos comenta J.I. Ferreras: “... Cádiz, 1842, Impr. de Núñez y Arjona, calle de San José núm. 46. Sólo puedo citar la obra de Juan J. de Arenas... que constituye el. primer tomo de esta colección” (p. 74, $\mathrm{n}^{\circ}$ 329). Esta novela de J.J. Arenas la reseñaremos en el apartado dedicado a la novela nacional; por otra parte, la relación Núñez-Arjona y éste con otros impresores dará sus frutos en la edición de novelas, como luego veremos.
} 
Arjona, 2 vols. $8^{\circ}, 1846^{43}$. Con Cantelmi publica también Arjona otra traducción de Paul de Kock, Juana o los tres mercados de flores, trad. libre por el Andaluz, Cádiz, $8^{\mathbf{0 4 4}}$.

\section{NOVELA NACIONAL.-}

-Arenas, Juan José de, Una revolución en Venecia, Cádiz, 1846, 304 págs., Impr. Núñez y Arjona. Constituye el número 1 de la "Biblioteca Popular Gaditana" [48, $\left.\mathrm{n}^{\circ} 142\right]^{45}$.

-Los misterios de Rusia. Cuadro político y moral, Cádiz, 1845, $8^{\circ}$ Impr. Núñez y Arjona [260, $\left.\mathrm{n}^{\circ} 1318\right]$.

-Moreno de Fuentes, José, Amor y venganzas de un esclavo, Cádiz, 1848, 8º [265, n 1359].

-Sánchez de Castilla, Gabriel, El anacoreta del Monte San Bernardo, Cádiz, 1864, 4º [371$\left.372, \mathrm{n}^{\circ} 1840\right]$.

-Idem, El castillo del Aguila Negra (novela histórica), Cádiz, 1869 [371-372, nº 1840] $]^{46}$.

-Idem, El aventurero castellano (novela histórica), Cádiz, 1861, [371-372, nº 1840] $]^{47}$.

-Idem, Guerra a muerte. Continuación del Aguila Negra (novela histórica), Cádiz, 1861 $\left[371-372, n^{\circ} 1840\right]^{48}$.

-Idem, Ludomilla de Ravensberg o el Castillo del Aguila Negra, Cádiz, 1847, 2 vols. 8, Impr. y Librería Arjona Cantelmi. En la "Biblioteca Popular Gaditana", [371-372, n 1840] $]^{49}$.

Del segundo y, a nuestro entender, más importante establecimiento tipográfico de Cádiz durante la segunda mitad del siglo XIX, la Revista Médica, dijo el propio Fernández Montesinos: "Nadie sospecharía que uno de los más activos agentes de difusión de novelas románticas y folletines fuera la Revista médica de Cádiz -sus talleres tipográficos, al menos-; si atendió a la medicina como a la literatura, merecerá figurar brillantemente en los

\footnotetext{
${ }^{43}$ Sobre este impresor, Núñez, recogemos de Montesinos otras traducciones salidas de sus talleres:

-Balzac, Honoré de, Rosita. Ecos de Castilla, o sean Recuerdos de España en 1838, (Apócrifo), trad. de Emilio Polanco, Cádiz, Núñez, $8^{\circ}, 1843$.

-Robert, Clemence, El Marqués de Pombal, nov. histórica, trad. libre de D. Antonio R. Guerra, Cádiz, Núñez, $8^{\circ}$, ("Colección de novelas traducidas y originales"), 1843.

-Sue, Eugène, Gardiki, recuerdo histórico del s. XVIII, puesto en castellano por Emilio Polanco, Cádiz, Núñez, 8, 1843 .

${ }^{44}$ Publicada por Cantelmi también recogemos en el "Esbozo" de Montesinos una novela: [Lavaissiere de] Lavergne, Alexandre de, Paulina Butler, trad. libre de Antonio R. Guerra, Cádiz, Cantelmi, 8, 1846.

${ }^{45}$ Entre corchetes la página y el número correspondientes a la reseña de autor y obra en el Catálogo de novelas.. de Ferreras.

46. Aunque Ferreras no señala la imprenta Arjona como la editora de esta obra, más adelante registra la anotación que sobre ella hace Hidalgo: El Castillo del Aguila Negra, Cádiz, 1862, (2ª ed.), 716 págs., 4º, Impr. y Librería Arjona" (p. 372).

${ }^{47}$ El mismo problema que en la anterior se presenta en esta novela. Hidalgo junto con Brown, Zellers y Palau señalan que esta obra se publica en Cádiz, en 1846, 4 tomos, $8^{\circ}$,Impr. Arjona Cantelmi, en la colección "Biblioteca Popular Gaditana". Y según este dato, en la denominada "Biblioteca Popular Gaditana" participarían como impresores Arjona, Núñez y Cantelmi.

${ }^{48}$ Según Hidalgo, Guerra a muerte. Continuación de El Aventurero Castellano. Cádiz, 1861 (2ª ed.), 1024 págs., $4^{\circ}$, Impr. y Librería Arjona".

${ }^{49}$.Ferreras recoge este título de Palau y Brown.
} 
anales de la Facultad"so. Y ciertamente que en actividad y concretamente en producción novelística, esta imprenta superó con amplitud cualquiera de las hasta ahora nombradas. Y para hacer el recuento de ello, distribuiremos nuestros datos en los mismos apartados que hemos utilizado anteriormente para la imprenta de Fernández Arjona.

\section{TRADUCCIONES.-}

-Anónima, Arturo y Julia o La Abadesa de Santa Elena, trad. del inglés, por D. Luis Moro, Cádiz, 1844, [261 $]^{51}$.

-Idem, Casarse por interés y buscarse por amor, Cádiz, 1844, [262] $]^{52}$.

-Idem, Tadeo Francisco o La víctima de su propia generosidad, Cádiz, 1844, [268] ${ }^{53}$.

-Bernard, Charles de, La caza de amantes ( La peau du lion et la chasse aux amants), 1841, Cádiz, [164].

-Castille, Charles Hippolythe, El Markgrave de Claris, arreglada al español para los folletines de "El Omnibus gaditano", Cádiz, 1844 [171].

-Cooper, James Fenimore, Doña Mercedes de Castilla o El viaje a Catay, trad. de D. Pedro A. O’Crowley, Cádiz, 1841, [177].

-Dumas, Alejandro, La hija del Regente, traducida expresamente para el folletín de "El Omnibus gaditano", Cádiz, 1844-45, [185].

-Idem, D'Artagnan y los tres mosqueteros, arreglada al español para la colección de novelas de la Revista Médica, Cádiz, 1845, [185].

-Féval, Paul, Los misterios de Londres, trasladada al español por Isidro M. de A., Cádiz, 1844, [191].

-Kock, Ch. Paul de, Bigotes, trad. de P..A. O’Crowley, Cádiz, 1841, [211].

-Idem, El barbero de París, vertida por P.A. O'Crowley, Cádiz, 1842, [211].

-Idem, Un recluta, Cádiz, 1842, [211].

-Marryat, Frédéric, La nave fantasma, trad. de P.A. O’Crowley, Cádiz, 1843, [224].

-Masson, Michel, llamado Michel Raymond, A la reina no se toca ( Ne touchez pas à la reine), trad. de P.A. O'Crowley, Cádiz, 1841, [223].

-Méry, Joseph, La condesa Hortensia, trad. de P.A. O’Crowley, Cádiz, 1843, [224].

-Scott, Walter, Guy Mannering, trad. de P.A. O’Crowley, Cádiz, 1843, [243].

-Soulié, Frédéric, Los pretendientes, trad. de P.A. O'Crowley, Cádiz, 1843, [246].

-Idem, El castillo de los Pirineos, trad. de D. J. M. de A., Cádiz, 1844, [247].

\footnotetext{
50.J.Fdez. Montesinos, Op. cit., p. 118.

${ }^{51}$ Mantenemos el número entre corchetes correspondiente a la página de la obra de Fdez. Montesinos en la que se reseña la novela citada. Por otra parte, esta obra también es citada por J.I. Ferreras en su Catálogo: pág.50, nº 164.

52. Novela también reseñada por J.I. Ferreras en su Catálogo: pág. 97, n 488.

${ }^{53}$ También en J.I. Ferreras, Catálogo: pág.391, nº 1945.
} 
-Idem, Consecuencias de una mañana borrascosa. Novela arreglada al español para insertarla en "La Estrella de Andalucía", Cádiz, 1844, [247].

-Sue, Eugenio, El palacio de Lambert, trad. de P.A. O’Crowley, Cádiz, 1843, [249].

-Idem, El judío errante, traducida expresamente para "El Omnibus gaditano”, Cádiz, 1844-45, [250].

-Tournachon, Félix, El manto de Deyanira, trad. de D. J.M. de A., Cádiz, 1844, [253].

-Waldor, Mélanie, Clotilde o la hija del tendero, trad. de D.M.M.B., Cádiz, 1841, [256].

A estas traducciones reseñadas por Fernández Montesinos, hay que añadir otras que hemos podido recopilar en distintas bibliotecas particulares, entre ellas:

-Anónima, Cesarina, Cádiz, 1861.

-Dumas, Alejandro, Lo que se ve todos los días, Cádiz, 1863.

-Idem, Los hermanos corsos, Cádiz, 1861.

-Souvestre, Emilio, El mendigo de San Roque, Cádiz, 1862.

\section{NOVELA NACIONAL.-}

-Benisia y Fernández de la Somera, Alejandro, El corsario negro. Novela marítima original, Cádiz, 1862, [62, n² 223 $]^{54}$.

-Garrido, Fernando, Lo que es el mundo, o memorias de un escéptico. Leyenda contemporánea, Cádiz, 1843, [174, n 846].

-Huet y de Allier, Luis, El fraile y el bandido, o las pasiones del claustro, Cádiz, 1843, [196, $\left.n^{\circ} 986\right]$.

-Idem, La hija del cardenal, Cádiz, 1844, [197, nº 986].

-Ibáñez Pacheco, Pedro, Cuentos gaditanos, con un prólogo de Nicolás Díaz Benjumea, Cádiz, 1877, [201, n 990].

-Laguna, el Señor de $1 a^{55}$ (¿seudónimo?), Los cuatro Juanes o los desposarios en el castillo de Zahara, Cádiz, 1842, [212, n 1039].

-Idem, La profesión frustrada, Cádiz, 1842, [212, nº 1039].

-León y Domínguez, José Mª Leyendas históricas y morales, Cádiz, $1866^{56}$.

-Luisa y Teodoro o los náufragos. Novelita original por D.L.M. (o B.) y de A., Cádiz, 1844, $\left[225, n^{\circ} 1128\right]$.

-Un retrato. Novela original por D.J.G. de A., Cádiz, 1842, [343, nº 1689].

-Rubio y Díaz, Vicente, Adelina. Leyenda fantástica, Cádiz, 1866, [359, nº 1781].

\footnotetext{
54.Mantenemos la página y el número correspondientes al Catálogo de J. I. Ferreras.

${ }^{55}$ Sobre este autor véanse las notas dedicadas a la imprenta de J.A. Niel en este mismo trabajo.

${ }^{56}$ Encontrada en biblioteca particular. Se trata de leyendas históricas anoveladas. El autor, según la presentación, es presbítero y catedrático en el Seminario Conciliar de San Bartolomé.
} 
-Sanz Pérez, José, Doña Luz y el fontanero. Cuento fantástico dividido en dos partes, Cádiz, $1847,\left[374, \mathrm{n}^{\circ} 1860\right]$.

-Idem, Los cuentos del peregrino, Cádiz, 1848 (en verso) [374, nº 1860].

-Idem, Artículos de costumbres, Cádiz, 1849, [374, n 1860].

-"Tiquis-Miquis", Las señoritas de nuestros tiempos, Cádiz, 1842, [398, n 1975].

-Velázquez y Sánchez, José, La huérfana de Bruselas, Cádiz, 1861, [423, n 2095].

La labor desempeñada por la Revista Médica en la difusión de la novela en Cádiz a lo largo del siglo XIX, como puede comprobarse por los datos reseñados, hemos de considerarla fundamental; supera con amplitud no sólo en número de publicaciones, tanto traducciones como producción nacional, la actividad desarrollada por las distintas imprentas que hemos visto y que también dedicaron parte de su esfuerzo a ello, sino también en otros aspectos tan importantes como el anterior; entre éstos, la colaboración de esta imprenta con periódicos de la época (traducciones que se insertan en los folletines de $E l$ Omnibus gaditano o en La Estrella de Andalucía) y la estrecha relación que al parecer mantenía con algunos traductores, entre los que destaca por su actividad Pedro Alonso O'Crowley. A todo esto habría que añadir dos facetas más: por un lado, la confección de la Revista Gaditana, una vez que ésta abandona los talleres de la Imprenta Gaditana de D. Esteban Picardo, a partir del número catorce (2 de febrero de 1840), y en la que hasta su desaparición se van a publicar variadas e interesantes narraciones: una traducción de la obra de Honoré de Balzac Miserias de la vida conyugal ( ${ }^{\circ} 15$ y 16), la novela de Pierre Angelo Fiorentino El Caballero Calabrés ( $\mathrm{n}^{\circ} 17$ y 18) y la de Alejandro Dumas Napoleón y Luciano $\left(\mathrm{n}^{\circ} 36\right)$, y muchos relatos de desigual extensión y todos anónimos: Magdalena $\left(\mathrm{n}^{\circ}\right.$ 19), Un corazón dividido ( $\mathrm{n}^{\circ} 21$ y 22), Una partida de ecarté y La predicción ( $\left.\mathrm{n}^{\circ} 23\right), \mathrm{La}$ sensible cartera $\left(\mathrm{n}^{\circ} 24\right)$, Manuel el Rayo. Novela de costumbres ( $\mathrm{n}^{\circ} 25$ y 26$)$, Un episodio del incendio de Pera ( $\mathrm{n}^{\circ} 27$ ), etc. ${ }^{57}$; y por otro lado, el negocio de librería que también poseía esta imprenta. En 1840 estaba ubicada la Revista Médica en la plaza de la Constitución $\mathrm{n}^{\circ} 15$, para pasar después a la calle de la Torre, esquina a la de Jardinillo ${ }^{58}$, y por posteriores referencias que nos ofrecen las Guías Oficiales de Cádiz a lo largo de la segunda mitad del siglo pasado, podemos saber que dicha imprenta estaba situada ya en 1867 en la calle Bomba 1 y Navas 13, a cargo de D. Federico Joly y Velasco, apellido a partir de aquí vinculado estrechamente a la historia de la imprenta en Cádiz; mientras que la librería, cuyo nombre era "Librería Española y Extranjera de la Revista Médica", tenía su domicilio en la plaza San Agustín 4 y 5 y estaba a cargo de los Sres. Verdugo, Morillas y Compañía.

Por último, aún nos queda por reseñar otra serie de novelas que, tomadas sus referencias de los dos catálogos manejados, publicadas en Cádiz no se indican en éstos la imprenta en que se confeccionaron. Recogemos de Montesinos dos traducciones: Mezelia de Henriette Arnaud (Mme. Charles de Reybaud), Cádiz, 1848, 2 vols. [158], y la obra de George Sand

\footnotetext{
57.Todas las referencias a la Revista Gaditana en V. Atero Burgos, "La Revista Gaditana... índice de contenidos", art. cit. En dicho artículo puede encontrar el lector reseña de todos los relatos que dejo sin citar por su prolijidad.

${ }^{58 . E n ~ V . ~ A t e r o, ~ " L a ~ R e v i s t a ~ G a d i t a n a . . . ~ E s t u d i o . . . ", ~ a r t . ~ c i t ., ~ p .8 . ~}$
} 
Lavinia y Metella, Cádiz, 1844 [201]. Y en cuanto a la novela nacional, del catálogo de J.I. Ferreras hemos recogido las siguientes:

-Alhamar, seudónimo quizá de Antonio de Benem, Biografía de un gato erudito escrita por él mismo, Cádiz, 1897, [36, n 54].

-Biedma, Patrocinio de, El odio de una mujer, Cádiz, 1882, [78, n 366].

-Idem, La boda de la niña. Novela original, Cádiz, 1885, [79, nº 366].

-Blanca de Montesa, Cádiz, 1858, [79, n 370].

-Böhl de Faber, Cecilia, Lágrimas. Novela de costumbres contemporáneas, Cádiz, 1853, [82, $\left.\mathrm{n}^{\circ} 385\right]$.

-Caballero Valero, Víctor, La azucena del valle. Leyenda popular, Cádiz, 1868, [89, n 420].

-Cambronero de la Peña, Manuela, Inés, Cádiz, 1846, [91, n 443] $]^{59}$.

-Causas célebres llamadas de la Mano Negra, Cádiz, 1883, [105, nº 518]. $528] .{ }^{60}$

-Clara-rosa o José Joaquín de Olavarrieta, Viaje al mundo subterráneo, Cádiz, 1820, [107, nº

-Los hermanos de Cecilia o la maldición de un padre, Cádiz, 1845, [192, n 946].

-Jamancio (seudónimo), Los misterios de Puerta Tierra, Cádiz, 1845-46, [205, n 1006].

-León Domínguez, José Mª , Leyendas históricas y morales, Cádiz, 1866, [215, nº 1065] $]^{61}$.

-Martínez de Lacosta (o La Costa), Rosa, El ángel del bien, Cádiz, 1878, [243, n 1204] $]^{62}$.

-Mejías y Escassy, Luis, La vieja del candilejo. Novela histórica, Cádiz, 1866, [250, n 1244].

-Idem, Las barricadas de Cádiz. Crónica..., Cádiz, 1869, [250, n 1244].

-Pug o Puig de la Puente, Francisco, La tumba ignorada. Leyenda cubana, Cádiz, 1855, [329, $\left.n^{\circ} 1638\right]$.

-’Rosas", Julio (seudónimo de un autor cubano), Flor del corazón. Novela india, Cádiz, 1857, [358, n 1775].

-Ruiz de Morales, Joaquín, La huérfana de Gibraltar. Episodios contemporáneos por J. R. de M., Cádiz, 1872, [196, nº 982].

-Sánchez Albarrán, José, El diablo mundo, Cádiz, 1872, [371, nº 1837].

-Un sueño de Amor. Novela fantástica original de D.M.G., Cádiz, 1847, [408, $\left.\mathrm{n}^{\circ} 2024\right]$.

-Viciana, Miguel, Martín León, Cádiz, 1899, [427, n² 2114].

-Zumel, Enrique, Los dos gemelos, Cádiz, 1845, [441, nº 2158].

\footnotetext{
${ }^{59}$ Según A. Labandeira, “Adiciones y precisiones...”, art. cit., p. 293, este autor publica dos novelas más en La Coruña.

${ }^{60}$.Sobre este autor véase supra la imprenta "La Sincera Unión"; y sobre la obra Iris M. Zavala, Ideología y política en la novela española del siglo XIX (Anaya, 1971) p.19.

${ }^{61 .}$ Por mi parte, he encontrado un ejemplar de esta obra impresa por la Revista Médica.

${ }^{62}$ En La Habana publica otra novela este autor, La deshonra de un nombre. Ver A. Labandeira, "Adiciones y precisiones...", art. cit., p. 306.
} 
A éstas hay que añadir una reseñada por A. Labandeira: El Corsario Negro, de Alejandro Berusia (novela marítima. Cádiz, 1862, dos tomos, en $4^{\circ}$ con láminas) ${ }^{63}$.

Para terminar y de acuerdo con todo lo dicho, podemos afirmar que la importancia y la trascendencia de Cádiz para la historia de España a lo largo de todo el siglo XIX, no pueden medirse exclusivamente por la serie de acontecimientos que en esta ciudad tuvieron lugar durante dicha centuria, el ambiente cultural del que disfrutó debe considerarse también un factor determinante o una muestra, quizá la más palpable, del esplendor de la ciudad. Vida cultural que se desarrolla fundamentalmente al amparo de una poderosa burguesía, y que tiene su representación más ilustrativa en el pujante negocio de las imprentas. Despliegan éstas su intensa actividad con la publicación de numerosos periódicos, auténtico termómetro del nivel cultural de un pueblo, y sobre todo, en lo que respecta a nuestros propósitos en este trabajo, con la publicación de esos "novelones" tan del gusto de todos los públicos en el pasado siglo.

${ }^{63}$ A. Labandeira, "Adiciones a un catálogo...", art. cit., p. 75. Se incluye este autor en los "nuevos no identificados" 
